Revista Mad. No.5. Septiembre 2001. Departamento de Antropología. Universidad de Chile http://sociales.uchile.cl/publicaciones/mad/05/paper05.htm

\title{
Representaciones de Género, Poder y Modelos de Gestión presentes en la Conversación Pública de Mujeres que ocupan Cargos Directivos en el Estado: El Caso del Ministerio de Agricultura
}

Alex Barril. abarril@segegob.cl Magíster en Antropología y Desarrollo. Universidad de Chile

\section{Resumen}

El estudio realizado, analiza un grupo de mujeres que ocupan cargos de dirección en organismos públicos y que tienen la posibilidad de tomar decisiones que orientan y determinan los modelos de gestión a aplicar en sus organizaciones. Es decir, están ubicadas en un espacio de poder que tradicional e históricamente ha sido y continúa siendo ocupado mayoritariamente por hombres.

¿Cuáles son las representaciones de género presentes en estas mujeres, cómo estructuran sus discursos o conversación pública, cómo ocupan un espacio tradicionalmente asociado a lo masculino y cómo el capital cultural o simbólico con el que cuentan, se traduce en un modelo de gestión particular?, son algunas de las preguntas que motivaron la realización de este estudio.

La principal intención de la presente investigación es, por lo tanto, adentrarse de manera analítica en las "voluntades personales y políticas" de los tomadores de decisiones en los organismos públicos, focalizando el análisis en aquellas mujeres que ocupan cargos directivos y en un contexto (el Ministerio de Agricultura) donde existe formalmente un interés por ocuparse del tema seriamente y más allá de la retórica.

En concordancia con lo anterior, este estudio se ha propuesto los siguientes objetivos:

\section{Objetivo General:}

$\pi$ Explorar y analizar las representaciones de género vinculadas a los modelos de gestión presentes en la conversación pública de mujeres que ocupan cargos de dirección en el Estado.

Objetivos Específicos.

I Identificar los elementos discursivos que facilitan u obstaculizan la incorporación de la temática de género en las organizaciones que dirigen.

- Explorar y describir las vinculaciones conceptuales entre Representación de Género y Modelos de Gestión Pública, en el contexto y ámbitos asumidos para el estudio.

Palabras Claves:

- Género y Poder

- Igualdad de Oportunidades

- Modelos de Gestión Pública

- Género y Discurso

- Políticas Públicas 


\section{Introducción}

En las últimas décadas, los estudios de género han tomado un lugar fundamental en la investigación social. En ellos se ha buscado hacer "visible" el papel de la mujer en nuestra sociedad, tanto en el nivel de su participación económica y política en los mercados de trabajo, como en su rol dentro de la familia y en los movimientos sociales.

En el presente trabajo, se analiza un grupo de mujeres que ocupan cargos de dirección en organismos públicos y que tienen la posibilidad de tomar decisiones que orientan y determinan los modelos de gestión a aplicar en sus organizaciones. Es decir, están ubicadas en un espacio de poder que tradicional e históricamente ha sido y continúa siendo ocupado mayoritariamente por hombres.

¿Cuáles son las representaciones de género presentes en estas mujeres, cómo estructuran sus discursos o conversación pública, cómo ocupan un espacio tradicionalmente asociado a lo masculino y cómo el capital cultural o simbólico con el que cuentan, se traduce en un modelo de gestión particular?, son algunas de las preguntas que motivaron la realización de este estudio.

La presente investigación - de carácter exploratoria - tuvo como escenario de fondo al Ministerio de Agricultura. Esto por dos razones fundamentales: uno, se trata del único organismo del Estado - distinto al Servicio Nacional de la Mujer - que a la fecha, mantiene vigente un plan de acción referido a materias de género e igualdad de oportunidades para sus funcionarios y funcionarias; y dos, por que cuenta con una inédita instancia de trabajo específica del tema, conformada por representantes de sus ocho organismos dependientes, llamada Comisión Asesora del Ministro de Agricultura en materias de Género.

En consecuencia, los sujetos de esta investigación son mujeres con cargos directivos en una secretaría de Estado actualmente considerada —en los hechos y según su propio discurso institucional- como "punta de lanza" en la incorporación de la perspectiva de género en la formulación y seguimiento de políticas públicas, uno de los principales objetivos del gobierno del Presidente Lagos, de acuerdo a lo definido por el Plan de Igualdad de Oportunidades para Mujeres y Hombres 2000-2010.

Resultaba, pues, particularmente interesante explorar en la conversación pública que estas mujeres realizan sobre el tema, tratando de colocar en perspectiva aquellos factores que facilitan y obstaculizan la incorporación de la temática de género en este ámbito -a través del Plan de Acción dispuesto para esos efectos-y con ello, entregar insumos de primera mano que permitan - eventualmente - formular estrategias de capacitación en la materia que sean más efectivas y penetrantes que las actuales.

Si el propósito del Gobierno ha sido, claramente, propiciar mayores y mejores niveles de "intervención" — desde el enfoque de género- en las dinámicas culturales existentes en los diversos ámbitos de acción y reflexión de la sociedad chilena: familia, educación, trabajo, salud, participación, ruralidad, pobreza y modernización del Estado, entre otros, resulta fundamental analizar el discurso de aquellos actores que movilizan estos propósitos y los transforman en actos o acciones concretas. Más aún, si estos actores son mujeres con cargos directivos, lo que supone un especial compromiso y mayor claridad sobre el tema y sus alcances.

Por otra parte, incluir la igualdad de oportunidades en los criterios de políticas públicas, ha requerido un papel activo del SERNAM, en tanto instancia responsable de impulsar y coordinar las políticas de género al interior del Estado. 
A partir de la aplicación del primer Plan de Igualdad de Oportunidades (1994-2000/ Gobierno de Frei Ruiz-Tagle), la equidad de género tiende progresivamente a legitimarse como criterio de elaboración de políticas, lo que se ha expresado — según lo señalan documentos del SERNAM ${ }^{1}$ en la apertura de instancias institucionales donde es posible abordar los problemas derivados de la desigualdad de oportunidades.

Sin embargo, de acuerdo a las evaluaciones realizadas por las mismas autoridades de Gobierno, los avances en la institucionalización de las acciones favorables a la equidad de género han sido menores y las políticas de género dependen todavía de las voluntades políticas y personales de autoridades y funcionarios; de la escasa formulación de indicadores de género específicos y adecuados a la intención de medir resultados e impacto de las políticas de igualdad; y de una mayor y mejor interacción entre el Estado y la Sociedad Civil como forma de establecer políticas que se vinculen de manera real y concreta a los intereses y problemas de las mujeres y hombres.

La principal intención de la presente investigación es, por lo tanto, adentrarse de manera analítica en lo que el diagnóstico del SERNAM Ilama las "voluntades personales y políticas" de los tomadores de decisiones en los organismos públicos, focalizando el análisis en aquellas mujeres que ocupan cargos directivos y en un contexto (el Ministerio de Agricultura) donde existe formalmente un interés por ocuparse del tema seriamente y más allá de la retórica.

Con ello se buscó, en primer lugar, conocer las estructuras discursivas de los directivos públicos referidas al tema de género, las motivaciones de sus decisiones en la materia y como ellas configuran un determinado modelo de gestión.

Y, en segundo lugar, contribuir en la identificación de aquellos aspectos simbólicos o culturales presentes en los directivos públicos, que facilitan u obstaculizan el proceso de incorporación de la temática de género en sus políticas y programas sectoriales y que pueden ser abordados en procesos de capacitación específicos.

En consecuencia con lo anterior, en las páginas siguientes se describen los resultados de un estudio empírico sobre las posiciones de mujeres directivas de organismos del Ministerio de Agricultura, en relación con la incorporación del enfoque de género como criterio de formulación y evaluación de políticas; y cómo dichas posiciones se traducen en determinados modelos de gestión pública.

El estudio consistió en la triangulación de la perspectiva de diversos actores en el espacio social e institucional del Ministerio de Agricultura, cuyas posiciones discursivas fueron analizadas a través de entrevistas individuales y una entrevista grupal. Los actores incluidos correspondieron a las siguientes clasificaciones:

a. Mujeres con cargos directivos nacionales, jefas de planificación estratégica y jefas de Recursos Humanos.

b. Informantes Calificados: miembros de la Comisión Asesora de Género del Ministerio de Agricultura.

En consonancia con lo anterior, en las páginas siguientes se describen los antecedentes empíricos sobre el tema, que ayudan a clarificar las razones de su realización, así como la presentación del sistema de objetivos generales y específicos que lo orienta, los ejes conceptuales que permitieron llevar a cabo el análisis y la estrategia metodológica utilizada.

La segunda parte de la investigación presenta los resultados organizados de acuerdo a las interrogantes del estudio y su propuesta teórica, así como las Conclusiones propuestas y los anexos correspondientes.

\footnotetext{
${ }^{1}$ Plan de Igualdad de Oportunidades para Mujeres y Hom bres, 2000-2010.
} 
Revista Mad. No.5. Septiembre 2001. Departamento de Antropología. Universidad de Chile http://sociales.uchile.cl/publicaciones/mad/05/paper05.htm

\section{I \\ PRIMERA PARTE}

\section{ANTECEDENTES}

2.1 Políticas de Igualdad de Oportunidades entre Hombres y Mujeres en el país

En el marco de los procesos sociales de los '70 y ' 80 las organizaciones de mujeres lograron instalar el enfoque de igualdad de oportunidades en la opinión pública chilena, de modo tal que en los años '90, en el contexto de reconstrucción democrática nacional, el tema de las desigualdades de género se asume como un tema prioritario del gobierno.

Los distintos Gobiernos de la Concertación han entendido el tema de la igualdad de oportunidades de género, principalmente desde la situación de las mujeres, argumentando que son quienes viven mayores iniquidades. La primera medida consiste en la creación en 1990 del Servicio Nacional de la Mujer (SERNAM), con rango Ministerial, que se aboca al estudio, diseño y tramitación de reformas legales, el diseño e implementación del Programa de Igualdad de Oportunidades para las Mujeres 1994 - 2000 y de diversos programas específicos para mujeres, intentos de incorporación de la variable género en políticas sectoriales (educación, salud), estímulo a estudios de género y otras iniciativas.

Algunos fundamentos de la política pública chilena dirigida a avanzar en la superación de las iniquidades entre hombres y mujeres son:

- A nivel ético, asegurar iguales oportunidades de desarrollo permite velar por el ejercicio de los derechos básicos de las personas, hombres y mujeres.

- A nivel de sociedad, la superación de las desigualdades permite mejorar la convivencia y la vida común.

- A nivel político, la superación de las desigualdades favorece a la construcción de un contexto de interacción con bajo nivel de conflicto.

- A nivel estatal, es misión del Estado abordar y superar cualquier tipo de desigualdades en el acceso a oportunidades de modo tal de ofrecer un mejor estándar de vida para todos los ciudadanos.

- A nivel nacional, favorece al proceso de construcción democrática y de convivencia, en tanto reconoce las diferencias existentes entre los distintos grupos sociales y se les asegura posibilidades de representación, organización y participación en las decisiones de orden público.

Las formas de operacionalizar y diseñar acciones desde el enfoque de género en la política pública aplicadas hasta ahora, han sido diversas: estimular la incorporación de las organizaciones de mujeres en las instancias de participación respetando sus tiempos y espacios, complementar las acciones sociales locales con iniciativas de especial interés para ellas, adicionar a los programas que involucran participación femenina instancias de cuidado infantil que alivianen su carga cotidiana, etc.

Las políticas, planes y programas de igualdad de oportunidades que se han implementado para las mujeres en el país pueden ser analizadas desde dos perspectivas. Aquellas políticas públicas a través de las que se comprende el rol que las mujeres desempeñan como agentes de la reproducción social. En estas las mujeres pueden participar de acciones que atienden a sus "necesidades prácticas" ${ }^{2}$, que son las que derivan del cumplimiento de sus roles de género y la satisfacción de las necesidades básicas.

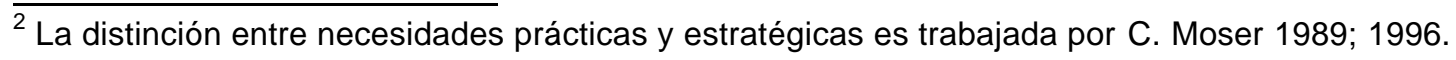


Pero también están aquellas políticas que se orientan a la satisfacción de las necesidades 'estratégicas de género', que son las que dicen relación con la situación de subordinación (falta de poder) y discriminación de las mujeres en el ámbito civil, laboral y socio-cultural. Acciones de este tipo debieran estar dirigidas a enfrentar los problemas derivados de su condición de mujeres para apoyar estrategias o políticas de empoderamiento y cambio de roles.

En general las acciones de igualdad de oportunidades inciden en las necesidades prácticas de las mujeres, ya que son de más fácil identificación, requieren de estrategias de acción más visibles y sencillas y refieren a beneficios y resultados concretos. Abordar los aspectos "estratégicos" de la situación social de las mujeres ha sido más difícil, porque requiere de procesos más largos y de intervenir en la relación entre hombres y mujeres.

Producto de lo anterior, muchas veces las políticas dirigidas a las necesidades prácticas terminan reproduciendo el rol tradicional de la mujer. Como afirma Errázuriz (1992) al realizar acciones en beneficio de la mujer hay dos riesgos importantes a tener en cuenta: instrumentalizar a las mujeres utilizándolas como un medio o instrumento de acción y que las acciones en su beneficio, en lugar de modificar su situación, la reproduzcan.

Un esfuerzo remarcable en esta línea, que pretende modificar la distribución de roles sociales y sexuales en la sociedad implementando acciones tendientes a la igualdad de oportunidades, lo constituye el denominado Plan de Igualdad de Oportunidades 2000 - 2010 impulsado por SERNAM.

\subsection{Planes de Igualdad de Oportunidades entre Hombres y Mujeres}

Luego de la creación del SERNAM en el año 1990 y de la implementación de un conjunto de acciones dirigidas a dar solución a los problemas específicos de las mujeres, que habían sido visualizados previo al proceso de redemocratización nacional, en 1994, se elabora un Plan de Igualdad de Oportunidades (PIO) 1994 - 1999. El propósito de este Plan es ser un instrumento clave en la coherencia y coordinación de la política social dirigida a las mujeres y convertirse en el eje articulador de la acción gubernamental en la materia.

En 1999 y basado en la evaluación de la implementación del PIO, el SERNAM impulsa la elaboración de un nuevo plan para la década siguiente. A diferencia del primer PIO, este tiene como propósito entregar los lineamientos generales y estratégicos para la acción pública pero ahora direccionada también a la intervención en la situación de los hombres.

A continuación se detallan de manera general algunas características particulares de cada uno de estos planes.

\subsubsection{Plan de Igualdad de Oportunidades $1994-2000$.}

Este plan se basó en las experiencias y conocimientos acumulados por las organizaciones de mujeres durante los ' 80 y tuvo como principal objetivo promover la redistribución entre los géneros de los recursos y tareas sociales, derechos civiles y participación, posiciones de poder y autoridad y valoración de las actividades que realizan mujeres y hombres.

El plan define objetivos y acciones concretas asociadas a cada objetivo. Cada ámbito de acción se fundamenta en un diagnóstico referencial acerca de la situación de la mujer. Los ámbitos que fueron abordados en este plan son: i) legislación; ii) familia; iii) educación; iv) cultura; v) trabajo; vi) salud; vii) participación y viii) fortalecimiento institucional.

El plan no tuvo una definición a priori acerca de la estrategia a partir de la cual actuar, por tanto las iniciativas fueron múltiples. La evaluación general de la implementación del plan reconoce como principales logros la instalación del tema de género en el Estado y la legitimación institucional del SERNAM como organismo encargado de coordinar y velar por las acciones dirigidas a las mujeres; 
y resultados en el campo de las políticas sociales que se traducen en el mejoramiento de la calidad de vida de las beneficiarias de esas políticas. Sin embargo, se reconocen escasos avances visibles en términos de la capacidad de interlocución de las mujeres con el Estado.

\subsubsection{Plan de Igualdad de Oportunidades $2000-2010^{3}$}

El diseño de este segundo plan, tuvo como base los aprendizajes obtenidos de la implementación del primero, en términos de estrategias de intervención, metodologías, definición de lineamientos, etc. Emerge de la constatación de que el contexto social, cultural y económico del 2000 difiere en importantes aspectos del de mediados de los '90. De tal modo, el diagnóstico de la situación de los géneros es también diferente.

El plan 2000 - 2010 pone énfasis especial en los nexos entre el cambio de las relaciones de género, en la superación de otras desigualdades, en la legitimación de la equidad de género como criterio de política pública y en la promoción de la participación y el control ciudadano en torno a las políticas de género.

Los temas en torno a los cuales se organiza este nuevo plan son: i) cultura de igualdad; ii) derechos de las mujeres; iii) participación en las estructuras de poder y en la adopción de decisiones; iv) autonomía económica de la mujeres y superación de la pobreza; v) bienestar en la vida cotidiana y calidad de vida y vi) enfoque de género en las políticas públicas.

A diferencia del primer plan, el segundo no propone objetivos ni acciones, sino que señala el sentido, los lineamientos y la meta a la que se aspira. Supone que la definición de las acciones es puesta a debate a partir de un diálogo interinstitucional.

La estrategia definida para la implementación de este plan, se sustenta en los aprendizajes del trabajo realizado para el primero y son: realización de estudios, diseño y coordinación de programas sociales de alto impacto, coordinación intersectorial y adecuación de las prioridades del plan a la realidad de las regiones y comunas del país.

Acorde con el propósito de incorporar el tema de género en las políticas públicas, algunos ministerios han comprometido con el SERNAM realizar acciones para incorporar dentro de sus agendas, programas y estrategias de acción vinculados al tema de género, pero también otros han avanzando en la elaboración de Planes de Acción para intervenir en la organización y dinámica de trabajo de sus funcionarios y funcionarias, de modo de asegurar entre estos iguales oportunidades laborales.

Los Ministerios que han desarrollado estas iniciativas son: Ministerio de Vivienda y Urbanismo, Ministerio de Bienes Nacionales y recientemente el Ministerio de Agricultura, siendo este último el único que mantiene una aplicación vigente. A continuación se detallan algunas características generales de cada uno.

\subsubsection{Plan Ministerio de Vivienda y Urbanismo}

El Ministerio de Vivienda y Urbanismo elaboró en 1998, un Plan de Acción de Igualdad de Oportunidades para sus funcionarias y funcionarios. El plan fue estructurado en a cinco áreas en torno a las cuales se constató mayor sensibilidad en el ministerio. Estas áreas se asumen como un punto de partida para institucionalizar la perspectiva de género en el MINVU. Estas áreas son:

- Institucionalización de la perspectiva de género

- Estrategia de Comunicación

- Capacitación

\footnotetext{
${ }^{3}$ Plan de Igualdad de Oportunidades para Hombres y Mujeres 2000 - 2010. SERNAM. Gobierno de Chile.
} 
- Recursos Humanos del MINVU

- Estudios de seguimiento.

Para cada área se definieron objetivos y acciones asociadas a los mismos, que debían ser implementadas de manera transversal en las acciones ministeriales, de modo de incorporar tanto al Nivel Central como a las Regiones. A la fecha, no existen antecedentes que den cuenta de una evaluación del impacto de este plan.

\subsubsection{Plan Ministerio de Bienes Nacionales}

El Ministerio de Bienes Nacionales, elabora en Julio de 1997 un Plan de Igualdad de Oportunidades para funcionarios y funcionarias. En el plan se definen beneficios directos a los funcionarios y funcionarias a través de la implementación de programas. Para cada acción se define una estructura responsable, los procedimientos de ejecución, los instrumentos y el cronograma. Por otra parte se definen actividades extralaborales y la necesidad de afianzar las relaciones sociales entre funcionarios/as.

Finalmente, se propone una etapa de difusión del plan que contribuya a la efectividad del mismo, para lo cual se diseña un cronograma de actividades y se incorpora a las Secretarías Regionales Ministeriales respectivas. Tampoco existen antecedentes de que den cuenta de los logros obtenidos y puntos de obstaculización presentes en la institución.

\subsubsection{Plan del Ministerio de Agricultura}

El Plan de Acción de esta secretaría de Estado, tiene por objeto lograr una cambio de mentalidad que apunte hacia el reconocimiento de las diferencias de género y realizar acciones positivas para generar una efectiva igualdad de oportunidades entre los funcionarios y funcionarias del Ministerio de Agricultura y sus servicios dependientes.

El Plan — que está programado para desarrollarse entre los años 2001 y 2010 — se estructura en 5 líneas de acción, para cada una de las cuales se ha planteado un objetivo general y un conjunto de objetivos específicos. Estas líneas son:

1. Difusión y socialización de las acciones y de las problemáticas de género en el ámbito laboral

2. Capacitación y sensibilización en temas de género

3. Producción de información desde una perspectiva de género, acerca de la situación laboral de trabajadores y trabajadoras

4. Beneficios laborales asociados a género

5. Condiciones laborales básicas para trabajadores y trabajadoras

El Plan de Acción ha sido diseñado, además, asumiendo que la tarea de operacionalizar los objetivos específicos, será de responsabilidad de cada uno de los servicios en que éste se implemente. Esto significa que los objetivos específicos deberán ser traducidos en acciones concretas, en función de las particularidades de cada servicio y que se deberá planificar su ejecución, definiendo etapas, tiempos, recursos y responsabilidades.

\subsection{Igualdad de Oportunidades entre Hombres y Mujeres en el Ámbito Laboral}

En el ámbito laboral, la inserción de hombres y mujeres ha sido marcadamente diferenciada. Esto se debe a la reproducción de los roles tradicionales asociados a lo masculino y lo femenino, en donde la mujer ha estado principalmente asociada al espacio privado, doméstico y familiar y el hombre al espacio público, a la producción social, cultural y económica.

En este contexto, el trabajo ha sido entendido como una labor eminentemente masculina, desconociendo los aportes de las mujeres en términos de trabajo no remunerado y sus potencialidades y capacidades de incorporarse en igualdad de condiciones en este espacio. 
Durante este último siglo, producto de las transformaciones socioproductivas y de las luchas de las mujeres, se han generado importantes transformaciones en el trabajo. Sin embargo, la inserción de los géneros en el ámbito laboral aún es desigual y diferenciada, presentando situaciones desfavorables principalmente para las mujeres, en términos de calidad del empleo y de las precarias condiciones laborales a las que pueden acceder.

\subsubsection{Situación de Hombres y Mujeres en el Ámbito Laboral}

La participación femenina en el mercado del trabajo es considerablemente inferior a la masculina. Mientras que la tasa de participación de los hombres en la fuerza de trabajo ascendía en 1998 al $74,6 \%$, la de las mujeres era sólo de $38,8 \%$ (Casen, 1998).

Al analizar la evolución de las cifras durante la década de los '90 se aprecia un leve aumento en el porcentaje de mujeres incorporadas a la fuerza de trabajo entre 1990 y 1996. No obstante, este porcentaje sigue siendo muy inferior al de participación masculina, sobre todo en las zonas rurales, donde sólo el $20 \%$ de las mujeres participan de alguna actividad económica remunerada.

Cuadro 1. Tasa de Participación en la actividad económica

\begin{tabular}{|l|l|l|l|}
\hline & Total & Mujeres & Hombres \\
\hline Total Nacional & & & \\
1990 & 51.6 & 31.3 & 73.6 \\
1996 & 54.4 & 35.5 & 74.6 \\
\hline Zonas Urbanas & & & \\
1990 & 52.0 & 34.2 & 72.1 \\
1996 & 55.4 & 38.1 & 74.5 \\
\hline Zonas Rurales & & & \\
1990 & 49.9 & 16.9 & 80.0 \\
1996 & 49.1 & 20.1 & 75.4 \\
\hline
\end{tabular}

Fuente: Las Mujeres Chilenas en los Noventa. Hablan las Cifras, CEPAL, 2000

No sólo es menor el porcentaje de mujeres que de hombres que trabajan, sino que además, las mujeres que participan del mercado laboral ganan, en promedio un 40,6\% menos que los hombres.

Cuadro 2. Promedio de ingreso mensual de la ocupación principal por sexo, 1998

\begin{tabular}{|l|l|}
\hline & $\begin{array}{l}\text { \$ de noviembre } \\
\text { de } 1998\end{array}$ \\
\hline Hombre & 293.451 \\
Mujer & 208.705 \\
\hline Total & 263.900 \\
Relación ingreso hombre/ingreso mujer & 40,6 \\
(\%) & \\
\hline Fuente: Encuesta CASEN, 1998
\end{tabular}

La brecha salarial se explica en parte por el tipo de empleos en que se concentran los hombres y las mujeres. Mientras que en las categorías "empleador" y "cuenta propia" es mayor el porcentaje de hombres que de mujeres, en las categorías "servicio doméstico" y "familiar no remunerado" se emplean casi exclusivamente mujeres. Entre los empleados, las mujeres predominan en el sector público ${ }^{4}$ y los hombres en el privado.

${ }^{4}$ El porcentaje de trabajadoras mujeres en el sector público es de $60,2 \%$, cifra que supera con creces la tasa de participación femenina en la población económicamente activa (que en 1998 alcanza el $36,1 \%$ ). La participación de las mujeres en la administración pública es especialmente 
Revista Mad. No.5. Septiembre 2001. Departamento de Antropología. Universidad de Chile http://sociales.uchile.cl/publicaciones/mad/05/paper05.htm

Cuadro 3. Distribución de los ocupados según la categoría ocupacional

\begin{tabular}{|l|l|l|l|l|l|l|}
\hline Categoría ocupacional & \multicolumn{2}{|l}{} & \multicolumn{2}{l|}{1996} \\
\cline { 2 - 7 } & Total & Hombres & Mujeres & Total & Hombres & Mujeres \\
\hline Empleador o patrón & 2.5 & 3.1 & 1.4 & 3.7 & 4.2 & 2.7 \\
\hline Cuenta propia & 22.4 & 24.6 & 17.8 & 20.3 & 22.1 & 16.9 \\
\hline Empleado & 65.9 & 69.5 & 58.6 & 69.0 & 70.9 & 65.3 \\
Público & & & 8.6 & 6.5 & 12.7 \\
Privado & & & 59.0 & 64.3 & 48.8 \\
\hline Servicio doméstico & 6.3 & 0.7 & 19.2 & 5.7 & 0.3 & 16.3 \\
Puertas adentro & 2.0 & 0.6 & 6.0 & 1.3 & 0.1 & 3.7 \\
Puertas afuera & 4.3 & 0.1 & 13.2 & 4.4 & 0.2 & 12.6 \\
\hline Familiar no remunerado & 1.8 & 1.3 & 2.9 & 1.3 & 0.8 & 2.2 \\
\hline FFAA y de orden & 0.9 & 1.3 & 0.2 & 1.3 & 1.8 & 0.3 \\
\hline Total & 100 & 100 & 100 & 100 & 100 & 100 \\
\hline
\end{tabular}

Fuente: Las Mujeres Chilenas en los Noventa. Hablan las Cifras, CEPAL, 2000

Gráfico 1. Porcentaje de Asalariados según dimensiones de precarización por sexo. Chile, 1994

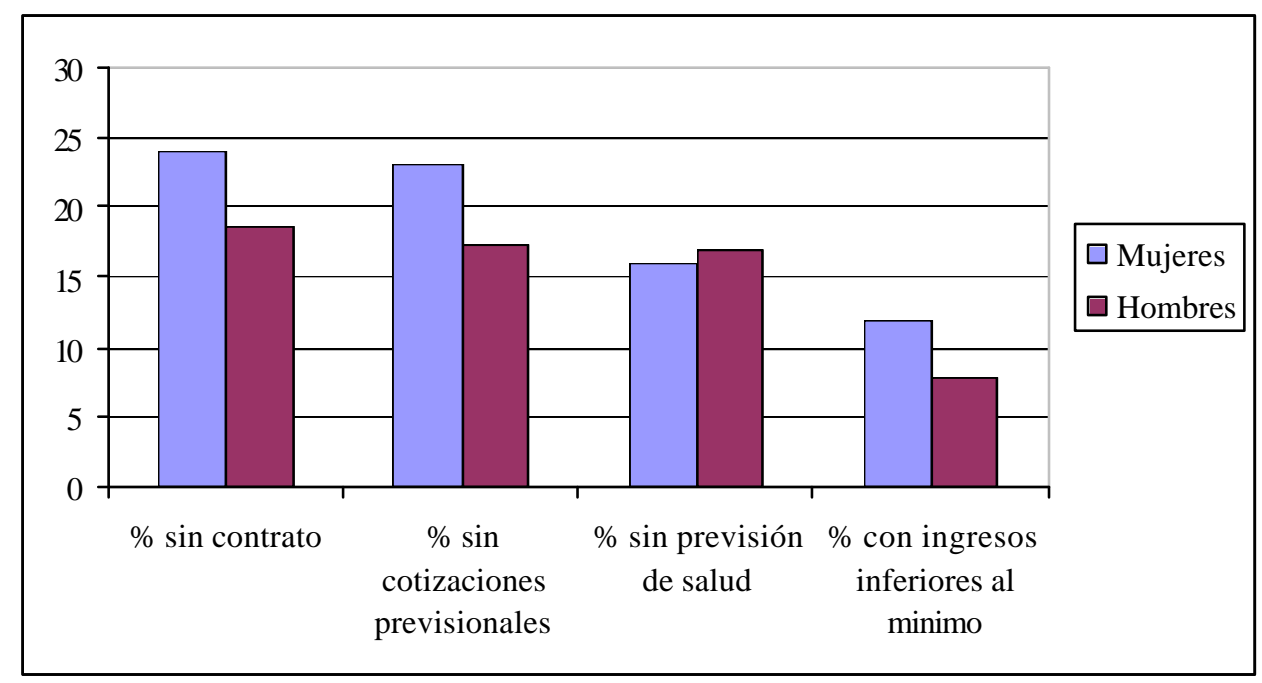

Fuente: Parada, 1999

Finalmente, además de obtener más bajos ingresos las mujeres tienen empleos más precarios que los hombres. Los porcentajes de mujeres sin contrato, sin cotizaciones previsionales y con ingresos inferiores al mínimo son mayores que los de hombres en la misma situación.

Sólo en lo concerniente a porcentajes de trabajadores sin previsión de salud es mayor el porcentaje de hombres que de mujeres, lo que se explica en parte, por la decisión de cotizar en forma independiente de las mujeres en edad fértil que se encuentran en condiciones de hacerlo.

significativa en los sectores sociales y fundamentalmente en el sector salud. Si no se considera el sector salud, el porcentaje de participación femenina en el sector público desciende a 44,2\% del total de empleos. ${ }^{4}$ La fuerza de trabajo femenina es más joven que la masculina, participa menos en puestos profesionales directivos y recibe, en promedio, un $30 \%$ menos de ingresos que sus pares. (Serrano, 1993) 
EI SERNAM se ha hecho cargo de este diagnóstico impulsando acciones para superar la iniquidad en materia laboral. Tanto a nivel de estudios como de diseño de acciones específicas, se ha abocado entre otros a los siguientes temas: estudios de costos laborales de trabajadores hombres y mujeres, formas en que ocurre el acoso sexual al interior de las empresas, empleo informal de las mujeres, jornadas de trabajo de hombres y mujeres, análisis de los regímenes de Isapres y AFP, entre otros.

Implementar planes de igualdad de oportunidades al interior de los ministerios forma parte de estas iniciativas y se define como un objetivo de especial relevancia, en la medida en que los organismos de gobierno han sido llamados a asumir el compromiso de superar las desigualdades de género, actuando en consecuencia y considerando en forma sistemática los efectos diferenciadores de hombres y mujeres en las políticas públicas de su sector (Plan de lgualdad de Oportunidades entre Mujeres y Hombres $2000-2010)$.

\section{OBJETIVOS DE LA INVESTIGACIÓN}

En función de los antecedentes presentados, queda en evidencia que las investigaciones y propuestas de implementación del tema de género en el aparato público, han privilegiado un enfoque macro y planes generales de "intervención" de las distintas realidades sectoriales que aborda la acción del Estado.

No se encontraron antecedentes $\rightarrow y$ esto no significa que no existan — de trabajos de investigación y formulación de programas destinados a indagar en las estructuras discursivas de los actores involucrados, aquellos que son responsables de la aplicación de los programas.

Para los efectos de este estudio, se asume que la "instalación" del enfoque de género en el Estado es un proceso de largo aliento, que no sólo requiere ser planificado y programado en el marco de la reestructuración y mode rnización del aparato estatal, sino que también conlleva un cambio en la mentalidad de sus actores.

Los avances en la institucionalización de las acciones favorables a la equidad de género —a juicio de algunos observadores del fenómeno- han sido menores, y el impacto positivo de las políticas de género dependen todavía en gran medida de las voluntades personales de autoridades y funcionarios.

Si focalizamos el análisis solamente en las autoridades mujeres y considerando los antecedentes presentados en relación a las diferencias en la inserción laboral de hombres y mujeres, se puede señalar - a modo de hipótesis de trabajo - que: a mayor nivel de jefatura o poder (toma de decisiones) que las mujeres alcanzan dentro de la organización pública, mayor es el nivel de incorporación de las nociones vinculadas a la temática de género y, al mismo tiempo, mayor la voluntad de cambio en la cultura organizacional en que se habita.

En ese contexto, el problema de la presente investigación corresponde a explorar las formas en que la temática de género es significada por las mujeres con cargos directivos en el Ministerio de Agricultura y las prácticas específicas que dichas representaciones detonan.

En concordancia con lo anterior, este estudio se ha propuesto los siguientes objetivos:

\subsection{Objetivo General:}

$\pi$ Explorar y analizar las representaciones de género vinculadas a los modelos de gestión pública, presentes en la conversación pública de mujeres que ocupan cargos de dirección en el Estado.

\subsection{Objetivos Específicos.}


$\pi$ Identificar los elementos discursivos que facilitan u obstaculizan la incorporación de la temática de género en las organizaciones que dirigen.

$\pi$ Explorar y describir las vinculaciones conceptuales entre Representación de Género y Modelos de Gestión Pública, en el contexto y ámbitos asumidos para el estudio.

\section{MARCO CONCEPTUAL}

Como ya se ha explicado, el foco de esta investigación está dado por el interés de aproximarse a las representaciones de género y modelos de gestión, presentes en la conversación pública de mujeres con cargos directivos en el Estado, específicamente, en el Ministerio de Agricultura.

La mirada conceptual desde la cual se busca explicar, analizar e interpretar el tema planteado para este estudio, está construida a partir de las siguientes entradas o ejes teóricos:

La primera de ellas, utilizará la noción de Representación Social postulada por Moscovici en el marco de la psicología social, así como los conceptos de capital institucional, conversación pública y preocupaciones, construidos a partir de algunos aspectos de la Teoría de la Conversación formulada por Jesús lbañez.

Una segunda entrada, utilizará el enfoque de género definido a partir de las nociones generales del concepto que se manejan en el gobierno (SERNAM) y se las vinculará analíticamente con definiciones más específicas de la materia, puntualmente, aquellas que entienden el género como relaciones significantes de poder y como estructuras de prestigio, postuladas por autoras como Joan Scott, Sherry Ortner y H. Whitehead, entre otros.

A continuación, se describe con mayor profundidad la perspectiva teórica propuesta.

4.1 Representación, Capital Institucional, Conversación Pública y Preocupaciones.

Toda gestión de gobierno se da en un espacio social en el cual existen actores con intereses más o menos convergentes en la definición de las reglas del juego o regulación de los diferentes sectores que componen el espacio social. Las reglas del juego o regulaciones de la participación de los actores en cada sector se establecen a través de políticas públicas sectoriales.

Con mayor o menor dificultad, el llamado "Sector Público" se encarga de articular dichas políticas teniendo por definición la misión de compatibilizar intereses que tienden a particularizarse y a hacerse más influyentes respecto de los otros. En ese sentido, todos los gobiernos deben resolver el problema de la administración de intereses distintos, a la cual ayuda la existencia de políticas sectoriales que, por definición, debieran expresar consensos básicos u apuntar a fines comúnmente valorados.

Para poder aproximarse a las representaciones sociales de determinados actores se requiere, por lo tanto, conocer los intereses circulantes en el espacio sectorial, el modo en que estos aparecen en el discurso público de los actores, y las posiciones que estos adoptan frente a determinadas temáticas, a partir de la evaluación que hacen de su influencia o participación en el juego de la construcción social y funcionamiento de las decisiones y regulaciones institucionales.

Para esto, puede ser útil considerar las nociones de capital institucional y conversación pública y preocupaciones.

Los actores o agentes de un espacio social confluyen al espacio sectorial dotados de repertorios diferenciales de capital institucional, lo cual determina las posiciones relativas que finalmente ocuparán en el sistema de influencia. A su vez, para administrar y proyectar efectivamente, el propio gobierno requiere de altos niveles de capital institucional, especialmente en el plano de la legitimidad o el capital simbólico. 
Los repertorios de capital institucional son puestos en juego en el espacio social, traduciéndose en una diversidad de posiciones y posicionamientos. De acuerdo a la posición de influencia que se alcance en función del repertorio de capital institucional disponible, se adoptará un posicionamiento diferencial frente a asuntos como las reglas del juego, el administrador de las reglas del juego y las posibles acciones propias a seguir en el juego social.

Las posiciones y el posicionamiento que se da en los diferentes sectores del espacio social sedimenta en lo que se denomina "representaciones sociales", las que no son otra cosa que repertorios discursivos construidos socialmente y relativamente comunes a grupos más o menos homogéneos de actores ${ }^{5}$. La importancia de las representaciones sociales radica en su relación con las prácticas efectivas.

Esta distinción es útil para los fines del estudio propuesto, ya que permite entender las representaciones sociales como variables en función de un determinado contexto o situación. De las representaciones se desprende un repertorio discursivo (argumentos) contingente, que postulará determinados temas, experiencias y motivaciones. En otras palabras, las representaciones serían discursos contextuales.

El acceso a ellas es posible a través del estudio del entramado discursivo que los actores tejen al interactuar en el espacio social. Dicho entramado es el producto de la "conversación pública", es decir, de la red comunicativa que es consustancial a la estructura social de actores diversos, pero situados en un mismo campo (en este caso el Ministerio de Agricultura) y con intereses puestos en su funcionamiento.

Los contenidos de la conversación pública de un espacio social pueden ser abordados genéricamente como "preocupaciones". Las preocupaciones sociales son la explicitación discursiva de representaciones interesadas de los actores en el sector, cuyo significado, sentido y valoración se relaciona con la experiencia concreta de tener una participación en el juego social, en el sistema de posiciones y posicionamientos derivados del "peso" del repertorio de capital institucional.

En los puntos siguientes se amplía la definición de los conceptos básicos de esta mirada conceptual.

\subsubsection{Capital Institucional}

Frecuentemente se piensa que el éxito de los proyectos —en este caso, la inserción de la temática de género en la formulación y seguimiento de políticas públicas - depende de la disponibilidad y ejercicio de poder, sin tomar en cuenta dos aspectos muy relevantes: que el poder depende de la existencia de capital, y que el capital es sistémico.

Esto quiere decir que la posibilidad de ejercer poder depende del equilibrio de los capitales económico, político, social, cultural y simbólico, y también quiere decir que los capitales interactúan en un sistema de influencias mutuas, donde muchas veces la existencia efectiva de capital económico y político depende del nivel de desarrollo de capital social, simbólico y cultural.

- El capital económico es la disponibilidad acumulada de recursos materiales, en la forma de inversiones, presupuesto, insumos o equipamientos físicos con valor de uso y/o de intercambio.

- El capital político es el potencial de influencia efectiva en las definciones normativas e institucionales de tipo público.

- El capital social es el conjunto y diversidad de vínculos o relaciones con otros, en términos de complicidades solventadas en la confianza y en la reciprocidad. Si bien esta categoría también

\footnotetext{
${ }^{5}$ Ibañez, Jesús. "El Regreso del Sujeto". Investigación social de segundo orden.
} 
es válida a nivel individual, a nivel de las organizaciones o proyectos admite la diferenciación de capital social interno y capital social externo. El interno habla de la fortaleza o debilidad de las prácticas de cooperación al interior de una organización, mientras que el externo apunta a la eventual red de alianzas generadoras de información y oportunidades en el medio.

- El capital cultural es el saber acumulado en una persona, organización o proyecto, donde se encuentran aspectos tales como el saber teórico, el saber metodológico, el saber tecnológico y el saber práctico.

- Por último, el capital simbólico es la dimensión del prestigio y la legitimidad de que disfrutan los actores en los diferentes campos en los que actúan, operando en este plano el "reconocimiento social" o "identidad pública".

\subsubsection{Conversación Pública}

El capital social y el capital simbólico son las coordenadas en las cuales se desarrolla y construye la conversación pública. La conversación pública es el entramado discursivo de un conjunto de actores o agentes que forman parte del juego social en un determinado espacio social. En dicha conversación los agentes sociales develan a través de sus interacciones comunicativas la estructura profunda de sus motivaciones, a la cual podemos denominar posicionamiento discursivo, preocupaciones 0 predisposiciones conectadas con prácticas efectivas o posibles, actuales 0 futuras.

En otras palabras, el conjunto de actores o agentes de un espacio social se comunica con base en o desde la subjetivación de su experiencia en el mismo, configurando el significado y valor de aquello que constituye el lei motiv de la existencia del respectivo ámbito (el o los focos de la conversación que los congrega y constituye).

Así en el caso de una implementación de políticas públicas desde la perspectiva de género, habría que identificar el conjunto de actores o agentes sociales que tienen intereses con el campo definido por la mencionada política, para así poder acceder a las preocupaciones indicativas de la significación y valoración subjetiva que le asignan a partir de su experiencia en la relación con ella. Dicha interpretación sería posible de establecer a través del estudio de la conversación pública sobre el tema de género, reproduciendo los discursos de manera programada y sometiendo los textos a través de los cuales se expresan a un análisis basado en categorías de interés.

El conocimiento obtenido sobre las preocupaciones de los agentes en la materia de interés, puede ser reproducido como una red de coordinaciones productoras de sentido común. En otras aproximaciones a estos temas se denomina a dicho proceso "reinyectar neguentropía" (introducir orden y coherencia a la conversación, en el marco de la reproducción o recreación de sentidos comunes, aún cuando sea desde intereses diferentes ${ }^{6}$ ).

\subsubsection{Preocupaciones}

En el estudio de la conversación pública interesa sobremanera comprender las preocupaciones como un sistema compuesto por una experiencia práctica, orientaciones motivacionales profundas y una tematización contingente. La experiencia práctica tiene que ver con el conjunto de vivencias del agente en el espacio social. Las motivaciones profundas con la estructura de aspiraciones y expectativas subyacentes a su conciencia. Y la tematización con la identificación referencial de los ámbitos de experiencia y motivación.

- La experiencia es discernible en los relatos acerca de lo que pasa, lo que ha pasado, lo que le pasa o ha pasado a uno, o lo que le pasa o ha pasado a otros.

\footnotetext{
${ }^{6}$ Teoría de Sistemas.
} 
- Las orientaciones motivacionales implican la definición explícita o implícita de necesidades, anhelos y estimaciones de posibilidad sobre la satisfacción de necesidades y el cumplimiento de deseos.

- Las tematizaciones derivan de las referencias objetuales de la experiencia o las orientaciones motivacionales, es decir, la experiencia es concreta y ocurre en relación con personas, cosas, lugares y tiempos, mientras que las orientaciones motivacionales apuntan a satisfactores.

Así la estructura de experiencias, motivaciones y tematizaciones de los actores de un campo permite discernir el mapa o cartografía de las preocupaciones, predisposiciones o posicionamiento subjetivo de los agentes, sobre cuyas coordenadas puede navegar efectivamente, por ejemplo, una política de capacitación en materia de género, produciendo los sentidos comunes que la coordinación ampliada exige, con base en el fortalecimiento continuo del capital social y el capital simbólico de la política pública y de su actor institucional, el Ministerio.

\subsection{Referencias Generales a la Categoría de Género}

El género es una construcción analítica que surge desde la corriente de pensamiento feminista norteamericana. Esta categoría aparece ligada a la necesidad de poder nombrar y entender las particularidades de hombres y mujeres asociadas a sus diferencias sexuales, sociales y culturales.

Históricamente, las diferencias entre hombres y mujeres han estado determinadas por sus diferencias biológicas, entendidas éstas como parte de una condición natural y esencial. Desde tales diferencias se han construido representaciones sociales y culturales acerca de ambos sexos, las que han relacionado al hombre, por ejemplo, con el ámbito de la creación de la cultura, con su rol de proveedor familiar y con el ámbito de lo público. Mientras que se ha entendido a la mujer, a partir de su relación con la maternidad, con su reproductivo, con el espacio de lo privado y lo doméstico.

Debido a que tales diferencias sexuales eran explicadas a partir de estructuras biológicas, "naturales", las diferentes identidades y representaciones que se construían se fundaban sobre estos mismos argumentos.

A diferencia de este pensamiento tradicional, la categoría de género, ofrece una nueva forma de acercarse a entender y explicar esas diferencias. Es una categoría eminentemente cultural y por tanto, no natural, que entiende que las representaciones masculinas y femeninas son históricamente construidas. "El nuevo concepto de género permitió entender que no es la anatomía lo que posiciona a mujeres y hombres en ámbitos y jerarquías distintos, sino la simbolización que las sociedades hacen de ella" (Lamas, M. 1999).

Desde esta mirada, hablar de desigualdades y discriminaciones entre hombres y mujeres adquiere un nuevo carácter. Estas diferencias desde la categoría de género se entienden, como producto de un orden social construido culturalmente, desde el cual "se ha reconocido a la mujer como diferente pero sólo para poner esa diferencia al servicio de una jerarquización genérica mediante la cual se le ha restado control sobre los recursos económicos, políticos e incluso morales" (González, M. 1995).

EI SERNAM, acogiendo los planteamientos de la Oficina de Condición de la Mujer de Canadá, sostiene que "el género es el conjunto de características culturalmente específicas que identifican el comportamiento social de las mujeres y de los hombres y la relación entre ellos. El género, por lo tanto, no se refiere simplemente a mujeres u hombres, sino a la relación entre ellos y a la forma en que ésta se establece socialmente. Debido a que es una expresión relacional, el género debe incluir a mujeres y hombres. Al igual que los conceptos de clase, raza y etnicidad, el género es una herramienta de análisis para comprender los procesos sociales" (SERNAM 1998). 
Hablar de género implica que las diferencias entre hombres y mujeres se da producto de una relación que se establece entre ambos. Desde esta perspectiva, intervenir en la superación de las desigualdades y discriminaciones de género, implica actuar sobre la relación. Esto significa reconocer y asumir que tanto hombres como mujeres, deben ser considerados como actores y protagonistas de este cambio.

\subsubsection{Género como Relaciones Significantes de Poder y como Estructuras de Prestigio.}

Para la historiadora Joan Scott, por su parte, el género además de ser un elemento constitutivo de las relaciones sociales basadas en las diferencias sexuales, constituye una forma primaria de "relaciones significantes de poder". De acuerdo a esta autora existirían cuatro dimensiones en las que se expresa el género, y que este estudio asume:

- Un nivel simbólico constituido por los símbolos culturales que evocan representaciones múltiples, incluidos los mitos.

- Conceptos normativos que constituyen las interpretaciones de los significados de los símbolos: doctrinas religiosas, educativas, científicas, legales y políticas.

- Nociones políticas y referencias a las instituciones y organizaciones sociales.

- La identidad subjetiva.

Para de Teresa de Barbieri (1996) la definición que Scott hace del concepto de género es fundamental en varios sentidos. En primer lugar, concibe el género como una cuestión social y no sólo de los individuos y sus identidades; en segundo término establece que el género es constitutivo de las relaciones sociales, conformando una construcción social compleja que halla expresión en varios niveles. Finalmente, subraya la particularidad de la definición de Scott, que considera el ordenamiento de género como una relación de poder, es decir, como relación social conflictiva, abriendo de este modo "la posibilidad de comprender que internamente, la relación de género es dinámica, capaz de cambiar y generar transformaciones sociales". ${ }^{7}$

Asimismo, autoras como Sherry Ortner y $\mathrm{H}$. Whitehead entienden el género como una estructura de prestigio. Estas autoras parten del supuesto de que el género y la sexualidad son construcciones culturales (simbólicas) y por lo tanto, se preguntan por el significado de lo femenino y lo masculino, en contextos sociales y culturales específicos.

Esta perspectiva precisa que el género sea analizado en su relación con un sistema más amplio de símbolos y significados interrelacionados. Es decir, no basta con preguntarse qué es ser hombre 0 ser mujer en una determinada cultura, sino que es más importante saber qué significados tienen tales definiciones dentro de esa cultura particular y cómo se relacionan con otros significados que se le asocian.

La estructura de prestigio se define como: la aplicación particular de la valoración social, a determinados grupos de individuos, de acuerdo a ciertas características que se consideran más importantes. Esto tiene como resultado el que los individuos y grupos alcancen determinados niveles o posiciones.

En las sociedades complejas existen distintos órdenes de prestigio, no sólo el género, por ejemplo el estrato socioeconómico, el linaje, etc. Mientras que en las sociedades más sencillas operan distinciones básicas como hombre/ mujer; hombres adultos/ hombres jóvenes. De este modo, el género es en realidad un sistema de prestigio utilizado como el criterio para crear diferencias que califican a los sujetos y los clasifican en una escala de inferior a superior. Para Ortner y Whitehead "en toda sociedad conocida, hombre y mujer son dos términos ponderados de distinta manera dentro de un conjunto de valores. Los hombres son, en tanto hombres, mejor valorados".

El género es entonces un proceso de configuración en la práctica social. La identidad de género, en tanto, corresponde a una simbolización cultural en que las diferencias anatómicas y fisiológicas

\footnotetext{
${ }^{7}$ de Barbieri, 1996.
} 
toman forma en un conjunto de prácticas, discursos y representaciones sociales que definen la conducta y la subjetividad. Todo sistema de representaciones es un sistema de legitimación de una estructura social particular y la gente que vive en ella percibe la estructura social como la manera en que las cosas deben ser.

\section{MODELO CONCEPTUAL PROPUESTO}

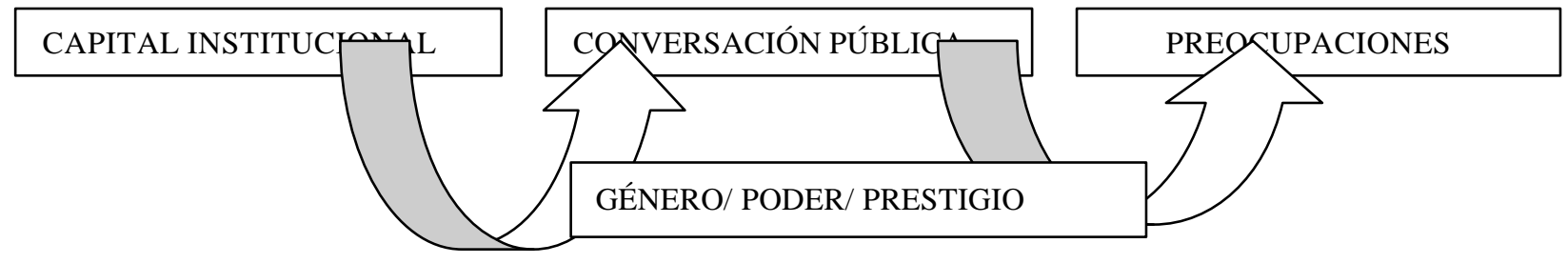

\section{ESTRATEGIA METODOLÓGICA}

Para responder a los objetivos y las interrogantes planteadas por el estudio, se contempló como estrategia metodológica el análisis de los tópicos o repertorios discursivos de los sujetos de la investigación, como medio para describir las representaciones que poseen en materia de género y cómo ellas se traducen, eventualmente, en modelos de gestión particulares.

Lo que se pretende, en términos metodológicos es la construcción de un "mapa discursivo" sobre el tema de género y gestión pública, en el cual sea posible "cruzar" los posicionamientos que los sujetos establecen de sí mismos y de otros actores para, con ello, dar cuenta de los sentidos que motivan la acción de los miembros del universo investigado.

Esto hacía recomendable focalizar el estudio en relatos de tipo individual, por lo cual se utilizó la técnica de entrevistas en profundidad — propia de la psicología social—guiadas por una pauta temática denominada de baja estructuración.

Este estudio comprende el proceso de investigación social como una dinámica en que interviene tanto el investigador como los sujetos que viven la realidad que se desea estudiar. Se señala esto, para dar cuenta del proceso de construcción del instrumento de producción de información que el presente estudio propone. La intención es poder entablar una buena relación con los entrevistados de manera tal que sea posible generar una confianza y un diálogo que permita aplicar entrevistas en profundidad.

Las entrevistas son una de las técnicas cualitativas que permiten acceder al sentido del sistema social. Se pueden definir como un "proceso comunicativo por el cual el investigador extrae una información de una persona contenida en la biografía de ese interlocutor, entendiendo como biografía al conjunto de representaciones asociadas a los acontecimientos vividos por el entrevistado. En este proceso el yo de la comunicación no es un yo linguístico, sino un yo especular o directamente social que aparece en un proceso en el cual el individuo se experimenta en función del otro generalizado, es decir, desde el punto de vista generalizado del grupo social al cual pertenece". 8

Se identifican actualmente tres tipos de entrevistas: la entrevista abierta o en profundidad, la entrevista semiestructurada y la entrevista estructurada. Este estudio utilizará como técnica de investigación la primera de ellas.

\footnotetext{
8. Alonso, L. E. "Sujeto y discurso: el lugar de la entrevista abierta en las prácticas de la sociología cualitativa.", en Métodos y técnicas cualitativas de investigación en Ciencias Sociales. Coordinadores: Delgado, J. M. y Gutiérrez, J. Ed. Síntesis Psicología.España. 1993. Págs. 225226
} 
La entrevista abierta o en profundidad, transcurre a través de una conversación entre el entrevistador y el sujeto entrevistado. Este tipo de entrevista se diferencia de los cuestionarios o entrevistas más cerradas, porque no existe una bateria de preguntas definidas en brma precisa para que el entrevistado conteste, si no más bien, una guía de la entrevista de manera que el investigador pueda asegurarse de abordar ciertos temas con el entrevistado. De esta forma, este instrumento asegura tanto una diversidad de preguntas significativas como una diversidad de probables respuestas con sentido.

Se trata, entonces, de incentivar el habla libre y espontánea de los sujetos en torno a ciertos temas eje que orientan la discusión y en donde el entrevistador adquiere el carácter ce provocador de estos temas, posibilitando que los entrevistados den sus puntos de vista.

La función básica que se le asigna a este tipo de entrevistas, es la de reproducir el discurso motivacional (consciente o inconsciente) de un sujeto "típico" perteneciente a un colectivo determinado, en este caso, mujeres con cargos directivos del Ministerio de Agricultura. Por consiguiente, lo que se intenta es rescatar los sentidos y las significaciones que hay detrás de las apreciaciones personales y que guardan relación con las características del colectivo del cual este individuo es miembro.

Si bien, a través de la entrevista no podemos comprobar que si lo dicho por el entrevistado representa la ideología del grupo o significados culturales compartidos del colectivo del cual forma parte (representatividad estructural), una serie de entrevistas es capaz de proporcionarnos una visión, al menos panorámica, de estos elementos.

El estudio se realizó entre octubre del 2000 y enero del 2001. El trabajo de campo, en tant o, se desarrollo durante los meses de noviembre y diciembre del 2000 y consistió en la aplicación de 3 entrevistas individuales a mujeres con cargos directivos en el Ministerio de Agricultura y 1 entrevista grupal a 8 informantes calificados, miembros de a Comisión Asesora del Ministro de Agricultura en materias de Género. El perfil de las entrevistadas se detalla más adelante.

\subsection{Universo del Estudio}

La muestra de la investigación, se construyó a partir de la observación del escenario del Ministerio de Agricultura ${ }^{9}$ y de la situación y condición de las mujeres funcionarias, específicamente, aquellas con cargos directivos y de acuerdo a estudios de diagnóstico organizacional realizados hasta la fecha ${ }^{10}$.

Estos estudios señalan que el Ministerio de Agricultura es una institución eminentemente masculina. En casi todos sus servicios es mayor la cantidad de hombres que de mujeres. Los hombres constituyen además, el grueso de universitarios de la institución.

En el Ministerio de Agricultura trabajan un total de 5.588 personas. La mayor parte de los/as funcionarios/as se concentran en CONAF, SAG e INDAP, que tomados en conjunto representan el $81 \%$ del total de funcionarios del Ministerio. El $31 \%$ de los trabajadores son mujeres y el $69 \%$ son hombres. La mayor presencia masculina es una constante en todos los servicios, a excepción de FIA y FUCOA, donde es mayor la cantidad de mujeres que de hombres y de la Subsecretaría de Agricultura, donde la diferencia a favor de los hombres es leve.

\footnotetext{
${ }^{9}$ Conformado por ocho organismos dependientes: Oficina de Estudios y Políticas Agrarias (ODEPA); Instituto de Desarrollo Agropecuario (INDAP); Servicio Agrícola y Ganadero (SAG); Corporación Nacional Forestal (CONAF); Instituto de Investigaciones Agropecuarias (INIA); Fundación para la Innovación Agraria (FIA); Fundación para las Comunicaciones del Agro (FUCOA); Comisión Nacional de Riego (CNR).

${ }^{10}$ Estudio de Diagnóstico de la Situación y Condición de funcionarios y funcionarias del Ministerio de Agricultura. Corporación Tiempo 2 Mil, año 2000.
} 
El $76,6 \%$ del total de funcionarios del Ministerio de Agricultura se desempeña en el nivel regional y sólo el $23,4 \%$ lo hace en el nivel central del Estado.

La edad promedio de los/as funcionarios/as de la institución es de 44 años. Mientras que los servicios con menor promedio de edad son los más pequeños (FUCOA, FIA), los mayores promedios corresponden al SAG, seguido de INDAP, dos de los servicios más grandes. Las mujeres son, en promedio, más jóvenes que los hombres (41,2 contra 45,3 años promedio).

Respecto del estado civil, la mayor parte de los trabajadores son casados $(77,9 \%)$, porcentaje que aumenta a un $83 \%$ en el caso del SAG y disminuye a un $63,3 \%$ en el caso de FUCOA. Según sexo, es considerablemente mayor el porcentaje de hombres que de mujeres casados/as. Del mismo modo, el promedio de hijos y de cargas es mayor entre los hombres que entre las mujeres.

Poco más del $40 \%$ de los/as funcionarios/as tienen formación universitaria completa. El nivel educacional que sigue al de los universitarios es el de formación técnica, con un $28 \%$ del total de funcionarios/as de la institución. En tercer lugar está el nivel de enseñanza media, que alcanza casi al $20 \%$ del total de trabajadores. Los servicios con mayor presencia de universitarios son FIA, FUCOA, INIA y la Subsecretaría de Agricultura. Respecto de la distribución por sexo, es menor el porcentaje de mujeres que de hombres con enseñanza universitaria.

Tomando la antigüedad promedio en la institución como un indicador de estabilidad en el empleo, los hombres que trabajan en el Ministerio de Agricultura tienen empleos más estables que las mujeres en la misma institución. Además los hombres acceden en mayor medida que las mujeres a cargos más altos, cuestión que se verifica por el hecho de que el porcentaje de hombres directivos y profesionales es mayor que el de mujeres, mientras que el grueso de los administrativos son mujeres.

La antigüedad promedio en la institución de los/as funcionarios/as del Ministerio de Agricultura y sus servicios dependientes es de 13,45 años. El promedio es mayor para los hombres (14,6 años) que para las mujeres (12,3 años). Mientras que FIA, FUCOA y en menor medida ODEPA promedian una antigüedad bastante inferior al promedio del Ministerio, los funcionarios de SAG, INDAP e INIA superan el promedio de antigüedad de la institución. A excepción del FIA, en todos los demás servicios es mayor la antigüedad de los hombres que de las mujeres.

Tomado el Ministerio de Agricultura en su conjunto y sin hacer distinciones según nivel educacional o ubicación en el escalafón de los funcionarios, los hombres que trabajan en la institución ganan en promedio un $19 \%$ más que las mujeres.

El porcentaje de funcionarias mujeres al interior de cada servicio fluctúa entre un $25 \%$ en el caso de CONAF y un $63 \%$ en el caso de FUCOA. Además de CONAF, también INDAP y SAG tienen poca presencia femenina lo que, agrega otra característica distintiva del grupo de servicios más grandes y antiguos: la escasa presencia femenina.

FUCOA destaca como el servicio con mayor presencia femenina en cargos directivos (el $100 \%$ de las directivas son mujeres). Lo siguen FIA $(71 \%)$, INDAP (32\%), ODEPA $(29 \%)$, Subsecretaría y SAG (17\%) y CONAF (8\%).

Considerando exclusivamente el estamento con mayor presencia de funcionarios en todos los servicios (profesional), las mayores diferencias en materia de remuneraciones se dan en el caso de FUCOA, donde los hombres profesionales ganan en promedio un $47 \%$ más que las mujeres.

\subsection{La Muestra.}

De acuerdo a los antecedentes esbozados, es posible realizar las siguientes precisiones que ayudan a justificar la construcción de la muestra. En primer lugar, sin contar a los actuales Ministro y Subsecretario de Agricultura (ambos hombres), de los ocho organismos dependientes que 
conforman la institucionalidad del Ministerio de Agricultura, sólo dos de ellos (FIA y FUCOA) -a la fecha de realización de este estudio- contaban con mujeres en su máxima jefatura. Por lo tanto, se decidió entrevistar a una de ellas y abordar así un primer nivel de la investigación que decía relación con los cargos máximos del Ministerio.

Se trata de una profesional, de 34 años, casada, tres hijos, que a la fecha de la investigación llevaba un año y medio de ejercicio de su cargo. A mediados de febrero el Ministro del ramo pidió su salida del puesto, por argumentos que hacían incapié en la necesidad de una persona cono "un perfil más político". La sucedió en el cargo, un hombre.

Otra área de toma de decisiones importante en esta repartición del Estado, es aquella vinculada al planeamiento estratégico. Del total de Jefes de Planificación Estratégica de los servicios del Ministerio de Agricultura (ocho), dos son mujeres (ODEPA, INIA). Por lo tanto, se decidió entrevistar a una de ellas.

Se trata de la persona que maneja los lineamientos estratégicos de la gestión ministerial, con un bajo perfil, con la responsabilidad de manejar un equipo pequeño, destinado a proponer y sintonizar medidas de gestión de acuerdo a los parametros del Programa de Modernización del Estado, impulsado por el Gobierno. Es una mujer de 50 años, separada, con un hijo, profesional.

Finalmente, una tercera área de decisiones institucionales que interesaba explorar en este estudio, es la referida a las políticas de recursos humanos. En este segmento, se repite la constante. La mayoría de las jefaturas de este ámbito son ocupadas por hombres, excepto en dos de ellas (FIA y CNR), una de las cuales fue incorporada a la muestra de la investigación.

La jefatura de recursos humanos en la institución escogida, no existía como instancia dentro del organigrama. Las funciones de administración, finanzas y bienestar estaban dispersas. La persona entrevistada es la responsable de su unificación. Se trata de una mujer de 40 años, casada, tres hijos, profesional.

Por otro lado, como una forma de verificar y contrastar la información obtenida en las entrevistas individuales, se decidió realizar una entrevista grupal con los miembros de la Comisión Asesora de Género del Ministerio de Agricultura —única instancia de su tipo a nivel gubernamentalconsiderándolos como informantes calificados en la materia. Esto último, sin dejar de considerarlos — dada su calidad de asesores - como sujetos de la investigación en cuanto a conocer las estructuras discursivas presentes en esta instancia.

Es así como, las entrevistas individuales fueron aplicadas a las siguientes mujeres en cargos directivos en el Ministerio de Agricultura:

Una Directora Ejecutiva (DE)

Una Jefa de Planificación Estratégica (JPE)

Una Jefa de Recursos Humanos y Bienestar. (JRH)

La entrevista grupal, en tanto, consideró a los siguientes informantes calificados, todos miembros de la Comisión Asesora de Género del Ministerio de Agricultura y representantes, en esa instancia, de los siguientes organismos:

\begin{tabular}{|l|}
\hline Corporación Nacional Forestal (CONAF) \\
\hline Fundación para la Innovación Agraria (FIA) \\
\hline Instituto de Investigaciones Agropecuarias (INIA). \\
\hline Instituto de Desarrollo Agropecuario (INDAP). \\
\hline Oficina de Estudios y Políticas Agrarias (ODEPA). \\
\hline Comisión Nacional de Riego (CNR) \\
\hline Jefe de Gabinete Ministro de Agricultura. \\
\hline
\end{tabular}


Subsecretaría de Agricultura

\subsection{Recolección de Datos.}

La recolección de datos se realizó a través de entrevistas en profundidad acerca del tema de género y modelos de gestión pública presentes en la conversación pública (preocupaciones/ repertorios discursivos) de las entrevistadas.

La pauta de las entrevistas individuales y grupal consideró los siguientes focos temáticos:

口 Definición básica: la construcción conceptual de género.

a Percepción sobre Género y relaciones de poder.

a Vinculaciones entre género y modelos de gestión femeninos y/o masculinos.

- Evaluación de las políticas gubernamentales sobre igualdad de oportunidades.

Las preguntas fueron formuladas, en general y de acuerdo a las dinámicas que se dieron en cada conversación, de la siguiente manera:

1. Cuál es el concepto o noción de género que se maneja, según tú percepción, en el Ministerio de Agricultura.

2. De acuerdo a tú experiencia, qué relación ves entre las nociones de género y poder.

3. Cuáles serían, a tu juicio, las principales características de un modelo de gestión pública masculino y uno femenino.

4. Cuál es la percepción general que tienes de las políticas de igualdad de oportunidades impulsadas por el Gobierno.

\subsection{Modelo de Análisis.}

Para el análisis se realizó un proceso de codificación abierta de cada una de las entrevistas individuales y grupal (intracaso) y luego se procedió a elaborar una matriz de análisis horizontal (intercaso), con el propósito de organizar los resultados (estructuras discursivas detectadas) de acuerdo a los focos temáticos ya descritos.

La matriz de análisis, es la siguiente:

\section{FOCO TEMÁTICO}

\begin{tabular}{|l|l|l|l|}
\hline Entrevistado & $\begin{array}{l}\text { Experiencias } \\
\text { La de uno }\end{array}$ & $\begin{array}{l}\text { Motivaciones } \\
\text { Necesidades }\end{array}$ & $\begin{array}{l}\text { Tematizaciones } \\
\text { Referidas a... }\end{array}$ \\
\hline & $\begin{array}{l}\text { La de otros } \\
\text { Positivas/ Negativas }\end{array}$ & $\begin{array}{l}\text { Aspiraciones } \\
\text { Expectativas }\end{array}$ & $\begin{array}{l}\text { Referidas a... } \\
\text { Referidas a... }\end{array}$ \\
\hline
\end{tabular}

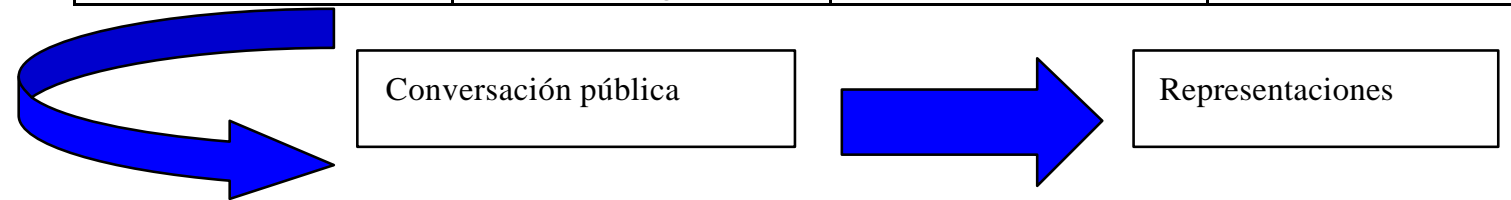

El propósito de este ordenamiento es establecer, a partir del análisis de la información, los aspectos discursivos que dan forma a la conversación pública de los sujetos investigados y, de ahí, las representaciones de género que manejan, tal cual fue fundamentado en el marco teórico del estudio.

Para ello, se realizaron las siguientes operaciones en el análisis de discurso, de acuerdo a los parámetros de la investigación social postulada por Jesus Ibañez, entre otros:

- Ver la "escucha": a través del subrayado. Lo que se dice.

- Paráfrasis, como dispositivo que describe lo subrayado, es decir, poner en palabras propias la escucha del otro (hacer la escucha). 
- La Glosa, entendida como hacer la escucha como quién esclarece el sentido más oculto o difícil de comprender. Es un intento por tratar de explicar la escucha.

- Estructuración: conexión de la unidad de análisis (dichos) a otros dichos en un contexto (totalidad). Este procedimiento, de acuerdo al modelo de análisis ya enunicado.

- Análisis comparativo de la enunciación (sujeto del discurso) con el enunciado (objeto del discurso).

\section{II \\ SEGUNDA PARTE}

\section{RESULTADOS}

En las páginas siguientes se exponen los resultados generales obtenidos tras la aplicación de las entrevistas individuales y la entrevista grupal. La sección está compuesta por los apartados: "Mujeres con cargos directivos" (resultados entrevistas individuales) e "Informantes Calificados" (resultados entrevista grupal). Tras cada uno de estos apartados, se consigna una nota conclusiva que sintetiza la exposición de los respectivos resultados.

La información, asimismo, está organizada de acuerdo a las interrogantes del estudio o focos temáticos propuestos: Definición básica: la construcción conceptual de género; Percepción sobre Género y relaciones de poder; Vinculaciones entre género y modelos de gestión femeninos y/o masculinos; Evaluación de las políticas gubernamentales sobre igualdad de oportunidades.

\subsection{Mujeres con Cargos Directivos}

Este apartado contiene los resultados obtenidos en cada foco temático a través de las entrevistas a las mujeres directivas. Algunas ideas expresadas refieren al informante específico que la sustenta. Al final hay una síntesis conclusiva.

\subsubsection{Definición básica: la construcción conceptual de Género.}

En las mujeres con cargos directivos entrevistadas se encuentran arraigadas una serie de preconcepciones tradicionales sobre lo masculino y lo femenino. Es coincidente la percepción de que entre los funcionarios del Ministerio, se ve a la mujer centralmente asociada al ámbito privado, lo que dificulta su incorporación al trabajo.

En cambio el hombre, dicen, se relaciona por esencia a lo público y al rol de proveedor. Estos roles son atribuidos a la estructura tradicional de la sociedad y a la "predominancia histórica del machismo" (DE) y se replican en el ámbito laboral, donde las mujeres son vistas como más aptas para trabajos administrativos y los hombres para la dirección y gestión.

En el ámbito familiar, los roles de madre, esposa y dueña de casa, son percibidos como parte de las responsabilidades intrínsecas de la mujer, y aparecen como un obstáculo para el desempeño laboral, en tanto deben combinarse ambas responsabilidades.

Se coincide en afirmar que los hombres ven a la mujer como débil, con menos potencia física y más delicada. Estas preconcepciones, se adaptan y replican en el ámbito laboral, asociadas al tipo de labores que se les asigna (trabajos administrativos) y las expectativas que se tiene de ellas.

Lo masculino se asocia con el ámbito público (trabajo). La responsabilidad de los hombres con la familia está asociada a su rol de proveedor. Las exigencias y expectativas laborales que se tiene del hombre refieren a esta responsabilidad. Los hombres son vistos como fuertes de carácter y con potencial físico. Se les visualiza más aptos para los trabajos directivos y el trabajo de terreno. 
Las mujeres que acceden a cargos directivos, tienen la exigencia de estar permanentemente validándose, esforzándose y mostrando sus resultados. Esta estrategia es lo que les permite ser valoradas y obtener el respeto laboral de parte de los demás funcionarios, hombres y mujeres.

En términos de convivencia y relaciones laborales, las entrevistadas observan dos tipos de opiniones opuestas respecto de las mujeres. Por una parte, el hecho de ser vistas como "hormonales", "complicadas", histéricas" y "extremadamente sensibles", lo cual dificulta el trabajo con ellas. Pero son también "ordenadas", meticulosas", "esforzadas", "organizadas" y "responsables", características, que se asocian con las responsabilidades de género (hogar) y que aparecen como un aporte para el desarrollo del trabajo.

En síntesis, si bien todas las entrevistadas dicen ser críticas a las concepciones tradicionales de género, reconocen lo determinante de dichas concepciones en el actuar de hombres y mujeres y la dificultad de quebrar con dichos paradigmas.

\subsubsection{Percepción sobre Género y relaciones de poder.}

La totalidad de las entrevistadas, coinciden al señalar que el tema de género tiene, hoy por hoy, una importancia más formal que real y, algunas de ellas lo grafican como un tópico "políticamente correcto" (JPE).

Asimismo, son enfáticas al recordar el dato que demuestra que las mujeres acceden en menor cantidad y posibilidad a los cargos de poder en el sector público, en comparación a los varones. En ese sentido, extrañan igualdad de condiciones y oportunidades a la hora de "competir profesionalmente más que políticamente" (DE) por un puesto o cargo dentro del Estado, pero reconocen las dificultades para ello.

Es aquí donde aparece uno de los aspectos más claros de los resultados de este estudio y es que, en relación con tema del poder — manifestando sus dudas acerca de una definición precisa y adecuada para este concepto- la asociación condicionante más clara es con la participación política, más que con el tema del género. "Las mujeres que alcanzan el poder ya pasaron una primera y dura selección: participan en política y han estado dispuestas a una lucha sin cuartel con sus correligionarios, para alcanzar las posiciones que hoy tienen" (JPE).

De igual forma, destacan una "mirada más humana" sobre el poder, por parte de las mujeres, la que se traduciría en acciones y decisiones más vinculadas a las personas. Este aspecto, se profundiza mayormente en el agregado destinado al tema de género y modelos de gestión.

Al momento de tratar de describir la relación del hombre con el tema del poder, hay una sola opinión: los hombres están más expuestos a factores de poder, tienden a funcionar en torno a dichos factores, tanto así que "las estructuras de poder están más pensadas en los hombres y sus conductas y expectativas que en las mujeres" (DE).

Finalmente, señalan que hay una mayor preocupación y celo —por parte de los hombres - por proteger los espacios/territorios de poder alcanzados. Además, identifican en ellos un mayor temor o sensación de amenaza relacionado con el ejercicio de estos cargos. Para las entrevistadas, esta situación no se da en las mujeres, ya que en ellas prima la necesidad y los criterios de gestión, más que el tema político partidista, que coinciden en señalar - nuevamente-como el factor determinante en las relaciones de poder que se dan en el sector público.

\subsubsection{Vinculaciones entre género y modelos de gestión femeninos y/o masculinos.}

Puestas a observar las eventuales diferencias entre los modelos de gestión masculinos y femeninos, asociados por las entrevistadas a las acciones y decisiones de hombres y mujeres respectivamente, se señalaron las siguientes ideas. 
El modelo femenino es descrito a través de lo que serían las características positivas, propias de las mujeres al ejercer cargos de poder. Estos elementos son: una visión más integral de las cosas, el privilegiar relaciones del tipo horizontal con las personas, ser más detallistas, motivadoras, más abiertas a nuevos aprendizajes, colaboradoras y que complementan de manera más clara los aspectos intelectuales con los emotivos. "En casos de crisis, la mujer está biológicamente mejor preparada que $\notin$ hombre para enfrentarlas. Porque siempre el hombre en estas circunstancias toma una actitud de víctima, que sufre y no da explicaciones" (JRH).

En el caso del modelo masculino, entendido como aquel desarrollado por los varones, las entrevistadas enumeran como características generales de este tipo de gestión, las siguientes: se privilegian relaciones más verticales con las personas, por lo tanto, más autoritarias; son modelos más individualistas, competitivos, con poca sintonía con el trabajo en equipo; hay un conocimiento más general del estado de la institución y se delegan menos responsabilidades. "Yo todavía no he conocido a ningún hombre que le preocupen las personas que trabajan a su cargo...es duro decirlo, pero es verdad"(JPE).

Se señala, además, que los límites "masculinos" establecidos a priori para ejercer un cargo público (toma de decisiones), dificultan obviamente la forma de actuar "femenina". Existe un modelo "mayor" legitimado(el masculino) que determina y condiciona el actuar de los directivos, sean hombres o mujeres, aún cuando ha sido desarrollado históricamente por hombres. "Es más difícil ser colaborador y horizontal que ser competitivo y vertical, es más difícil estar en sintonía con el grupo que marcar un territorio individual" (JRH).

Las entrevistadas coinciden en señalar, asimismo, que si bien estas características no están negadas para el género opuesto, ellas responden a un proceso de socialización más profundo que afecta tanto a hombres como mujeres y que, al mismo tiempo — según señalan- "atenta" contra cualquier cambio de mentalidad al respecto. Este aspecto, que nos vincula a relaciones más culturales será trabajado en el apartado de las conclusiones.

6.1.4 Evaluación de las políticas gubernamentales sobre igualdad de oportunidades.

En una mirada más global sobre el tema de las políticas gubernamentales, se recogen opiniones que apuntan a manifestar la necesidad de una mayor y real participación de la gente, en función de obtener mejores niveles de credibilidad de la acción de gobierno. Esto es graficado por las entrevistadas (DE) como el propiciar estados de escucha atenta y activa, así como el desarrollo de la autocrítica como recurso clave a la hora de evaluar y replantearse las decisiones.

Al mismo tiempo, también en términos generales, se requiere asegurar la profesionalización de los cargos de dirección pública, como una forma de situar el tema en su verdadera importancia, "trascendiendo con ello al tema político e incluso al aspecto de género" (DE).

Está la impresión de que el tratamiento "en abstracto" de los temas valóricos, societales y políticos, en la formulación de políticas gubernamentales, no moviliza a las personas. "La gente no tiene un marco teórico sobre estos aspectos, como tuvo nuestra generación (sesentas)"(JPE). Se plantea que si detrás del concepto de género se percibiera la posibilidad de logros personales, concretos, el tema generaría una mayor dinámica y compromiso de participación y cambio. "Creo que falta salirse del discurso de buena crianza, para convencer a hombres y mujeres que no quieren convencerse o que tienen esquemas inexpugnables, para entrarle a las cosas concretas. Poner indicadores de igualdad de salarios, otorgar un día al mes a las mujeres para atender asuntos familiares, como llevar a los chiquillos al médico, ir a los colegios, comparar para la familia, etc. Por ahora creo que lo laxo de las políticas es lo que desincentiva la participación" (JPE).

\subsubsection{Síntesis Conclusiva del Apartado Mujeres con Cargos Directivos.}

A modo de síntesis de las ideas expresadas en este apartado, se pueden mencionar las siguientes: 
> Producto de una concepción de género tradicional, que sitúa a hombres y mujeres en roles predeterminados en lo público y lo privado, respectivamente, las mujeres que acceden a cargos directivos, tienen la exigencia de estar permanentemente validándose, esforzándose y mostrando sus resultados. Esta estrategia es lo que les permite ser valoradas y obtener el respeto laboral de parte de los demás funcionarios, hombres y mujeres.

> La vinculación más clara, directa e importante se da entre poder y participación política, más que con el tema del género. Las mujeres que alcanzan el poder ya participan en política y han estado dispuestas a una "lucha sin cuartel" con sus correligionarios, para alcanzar las posiciones que hoy tienen. A la hora de acceder a un cargo público, es más determinante la pertenencia y apoyo del ámbito político partidista, que otros aspectos o factores, entre los cuales están el género o la capacidad profesional.

> Las entrevistadas señalan que los límites "masculinos" establecidos a priori para ejercer la toma de decisiones en el ámbito público, dificultan un eventual modo de actuar más cercano a los patrones "femeninos" por parte de los directivos, sean estos hombres o mujeres.

> Al momento de opinar sobre los alcances de las políticas públicas en materias de igualdad de oportunidades, se plantea que si detrás del concepto de género se percibiera más claramente la posibilidad de logros personales, concretos, específicos, el tema generaría una mayor dinámica y compromiso de participación y cambio. Se califica como "laxos" y muy "abstractos" los contenidos que dan forma a planes de acción de los entes de Gobierno responsables del tema.

\subsection{Informantes Calificados.}

A continuación se presentan los resultados surgidos a partir de la entrevista grupal realizada a los miembros de la Comisión Asesora del Ministro de Agricultura en materia de Género, considerados en el presente estudio como informantes calificados.

\subsubsection{Definición básica: la construcción conceptual de Género.}

Los entrevistados coinciden en señalar que en el Ministerio de Agricultura, el concepto de género está presente pero no se encuentra para nada asumido en el ámbito directivo. De hecho, plantean los entrevistados que en algunas esferas de decisión, conformada solo por hombres, las ideas que implica la noción de género son consideradas como "amenazadoras", si el tema es abordado en serio.

Se vuelve a mencionar, al igual que en los resultados de las entrevistas individuales, que la concepción de género presente en el Ministerio de Agricultura es tradicional, que repite los esquemas de relaciones familiares entre hombre y mujer y los traslada al ámbito laboral.

Se percibe al hombre como una persona menos sensible que la mujer y con una mayor necesidad de una formación emocional. "En el hombre lo emocional no está desarrollado, está abandonado, no se le refuerza". Esto, ha llevado a esta instancia a privilegiar la idea de "igualdad de oportunidades" por sobre la de género que —según señalan- es una noción que genera demasiadas resistencias en los hombres.

\subsubsection{Percepción sobre Género y relaciones de poder.}

Los entrevistados señalaron que para las mujeres que ejercen cargos directivos, esta situación implica doble carga de trabajo: la función laboral propiamente tal y la familiar. Califican esto como una marca que "se lleva encima"y es muy difícil de cambiar. Por otro lado, es precisamente esta característica de estar siempre en "varios lugares al mismo tiempo y haciendo mil y una cosas", la que hace más generosas a las mujeres con el tema de poder, ya que lo delegan o lo comparten sin problemas. 
Los hombres, por su parte, acceden a cargos de jefatura en el ámbito público por un factor político más que por capacidades y mantienen una relación de mucha dependencia con el poder. "A los hombres les cuesta liberarse del poder, porque les gusta tener poder, la mujer no tiene problema con eso, es capaz de repartir y compartir el poder, porque es más práctica".

De igual forma, el sistema político - tal como funciona en la actualidad- es concebido por los entrevistados como ámbito con un fuerte componente de poder y lo visualizan como "muy poco compatible con las destrezas y habilidades de las mujeres".

\subsubsection{Vinculaciones entre género y modelos de gestión femeninos y/o masculinos.}

Respecto de los resultados de las entrevistas individuales, en esta entrevista grupal - destinada a verificar ciertos aspectos recogidos - aparecen asociaciones que vinculan el modelo de gestión femenino con las ideas de lo "maternal" y lo "aprensivo". Estos, como características propias de las mujeres, que posibilitarían un estilo de liderazgo y/o autoridad más horizontal.

Se considera que la mujer ocupando puestos de poder, es más franca y directa que el hombre; éste último estaría "atrapado" en moldes políticos tales, que lo "obligan" a desarrollar modelos de gestión verticales, distantes y autoritarios, como única forma de mantener sus parcelas de poder.

\subsubsection{Evaluación de las políticas gubernamentales sobre igualdad de oportunidades.}

La única expresión referida a las políticas gubernamentales, señala que lo fundamental es reforzar el tema educacional. Tratar de formar personas que desarrollen "sus facetas masculinas y femeninas" de manera integral. Con ello, se podría comenzar a revertir una formación familiar "sumamente machista y patriarcal".

Curiosamente, a pesar de plantearse el tema explícitamente durante la entrevista, no se registran opiniones específicas sobre los alcances de las políticas de igualdad de oportunidades. Se habla de ellas en términos generales calificándolas como "positivas "y "de largo aliento".

\subsubsection{Síntesis Conclusiva del Apartado Informantes Calificados.}

DEn algunas esferas de decisión, conformada solo por hombres, las ideas que implica la noción de género son consideradas como "amenazadoras" y no se encuentra del todo asumido.

> Para las mujeres que ejercen cargos directivos, esta situación implica doble carga de trabajo: la función laboral propiamente tal y la familiar. Califican esto como una marca que "se lleva encima"y es muy difícil de cambiar.

D De igual forma, el sistema político es concebido como ámbito con un fuerte componente de poder y lo visualizan como "muy poco compatible con las destrezas y habilidades de las mujeres".

> Se considera que la mujer ocupando puestos de poder, es más franca, participativa y directa que el hombre; éste último estaría "atrapado" en moldes políticos tales, que lo "obligan" a desarrollar modelos de gestión verticales, distantes y autoritarios, como única forma de mantener sus territorios de poder.

$>$ Sobre los alcances de las políticas de igualdad de oportunidades, se habla de ellas en términos generales calificándolas como "positivas "y "de largo aliento". 


\section{CONCLUSIONES GENERALES}

Las conclusiones generales son presentadas atendiendo al orden de los objetivos del estudio y tratando de integrar las conclusiones parciales de los apartados anteriores.

En el supuesto que motiva la realización de este estudio, se afirma que la "instalación" del enfoque de género en el Estado es un proceso de largo aliento, que no sólo requiere ser planificado y programado en el marco de la reestructuración y modernización del aparato estatal, sino que también conlleva un cambio en la mentalidad de sus actores y, al entrar en ese ámbito, estamos incorporando la variable cultura en el análisis.

Las implicancias de esta relación género/ cultura, de alguna manera han sido recogidas por los resultados de este trabajo, así como otras aristas del tema que no estaban dentro de los resultados esperados de la investigación, a partir de la formulación de su hipótesis de trabajo.

\subsection{Relato de la experiencia de trabajo.}

Este apartado reúne las ideas surgidas a partir de la experiencia personal adquirida con la realización del trabajo. Si bien tiene un carácter testimonial que se aleja de la ortodoxia establecida para este tipo de informes, me pareció importante dar a conocer algunas de las reflexiones que surgieron a medida que el trabajo avanzaba, se estancaba, se transformaba, etc.

Lo primero que me gustaría señalar es que el modelo teórico planteado fue de mucha utilidad a la hora de encontrar un prisma para leer el tema de las representaciones de género, definiendo a éstas últimas como las portadoras del capital cultural o simbólico de los sujetos del estudio. Las nociones de experiencia, motivaciones y tematizaciones como elementos que dan cuenta de la preocupación (repertorio discursivo) del sujeto sobre un determinado tema y a partir de ahí, develar las conversaciones sostenidas al respecto en un espacio público, fueron una malla conceptual muy útil a la hora de analizar la información recopilada.

Los problemas, a mi juicio, estuvieron en los procesos de definición de la muestra del estudio y en la aplicación de las técnicas de levantamiento de datos, en este caso, las entrevistas en profundidad. Y esto, no sólo por problemas de cruce de agendas que hacían difícil acceder a las pocas mujeres con cargos directivos en el Ministerio de Agricultura, sino que por el hecho $\rightarrow \mathrm{y}$ esto a la luz de las respuestas_- de que el discurso presente en ellas, está demasiado "afectado" por la variable participación política, como condición determinante de su presencia en el cargo, la continuidad, su proyección, así como de los estilos de gestión que realizan. Y esta, es la primera de las conclusiones del estudio.

Sería interesante, por lo tanto, abordar este mismo estudio en jefaturas o mandos de mujeres en los niveles medios y bajos de una institución pública, donde el tema político es secundario (incluso accesorio) y donde se presentarían, de manera más clara aún, las variables culturales que perfilan las distintas representaciones y conductas en una determinada gestión.

En cuanto a la técnica escogida —entrevista en profundidad- resultó muy productiva para aquellas que respondieron a una modalidad individual, donde la conversación abierta permitió "navegar" por las distintas asociaciones al tema que surgiesen en el momento. Sin embargo, en la modalidad grupal, aplicada a la comisión asesora de género, el tema se tornó confuso respecto de la efectividad de la técnica. Tengo que ser franco al reconocer que, dada la dinámica de la conversación sucedida entre personas que tienen una relación laboral frecuente (reuniones semanales), el tema se focalizó en uno o dos aspectos y no abordó otras áreas deseadas, pese a la pauta de preguntas. Por momentos, daba la impresión de estar escuchando una sola voz y, si bien eso fue funcional a los objetivos del estudio, quedó la sensación de "gusto a poco". Quizás, con la eventual aplicación de otras técnicas (grupos focales o grupos de discusión), que plantean como pre-requisito el entablar conversaciones entre personas que no se conocen, hubiese sido más enriquecedor para la investigación. En esta decisión, el factor tiempo fue clave. 
En definitiva, se trató de una experiencia interesante que, dados los resultados y las conclusiones que a continuación se reseñan, entrega un insumo a considerar a la hora de proponerse estrategias de "intervención" en quienes son los tomadores de decisión en el ámbito público, tanto para el tema de género como para otros temas de igual trascendencia.

\subsection{Empezando a desentrañar la hipótesis de trabajo:}

A mayor nivel de jefatura o poder (toma de decisiones) que las mujeres alcanzan dentro de la organización pública, mayor es el nivel de incorporación de las nociones vinculadas a la temática de género $y$, al mismo tiempo, mayor la voluntad de cambio en la cultura organizacional en que se habita.

\subsubsection{El discurso de género y poder presente en las mujeres con cargos directivos.}

En los resultados el estudio, se manifiesta una tendencia a reproducir - de manera consciente 0 inconsciente - los patrones de conducta que hombres y mujeres han aprendido y adiestrado respectivamente en el ámbito familiar. La concepción tradicional de género que se "denuncia" por parte de las entrevistadas, da cuenta de un espacio social donde las representaciones de lo masculino y lo femenino está fuertemente determinado por las preconcepciones clásicas del tema: hombres proveedores, fuertes, autoritarios, individualistas, competitivos, autosuficientes, inmaduros emocionalmente, racionales, lógicos, apegados al poder, jerárquicos etc., versus mujeres maternales, colaboradoras, aprensivas, débiles, sensibles, emotivas, impredecibles, volubles, dependientes, generosas, empáticas, horizontales en sus relaciones, etc.

Lo interesante aparece cuando, en el contexto de las instituciones públicas, los roles predeterminados o esperados para hombres y mujeres, de acuerdo a la socialización que han tenido en sus vidas, comienzan a desestructurarse producto de nuevas prácticas. Mujeres que acceden a cargos de poder y se sienten tanto o más cómodas en esas aguas que los hombres, desarrollando facetas de asertividad, racionalidad, don de mando, competitividad, supuestamente propias de los varones más experimentados. $\mathrm{Y}$, al mismo tiempo, varones que poco a poco comienzan a desarrollar aspectos más emocionales, a privilegiar el trabajo en equipo, a preocuparse por los tiempos de ocio de su personal, en fin, los roles parecen mezclarse y confundirse crecientemente, a ojos de un observador tradicional y conservador.

Algo de aquello se presenta en las entrevistas incluidas en este trabajo. El significado de lo masculino y lo femenino está fuertemente asociado a hombres y mujeres respectivamente y no es visto como facetas intercambiables. Aún cuando, afuera de sus propias oficinas el mundo cambia lenta pero profundamente, en ese sentido. No hay, en las mujeres entrevistadas, una concepción de género que lo entienda como relacional. La tendencia, por el contrario, es a representar a los hombres y a las mujeres en función de las estructuras de prestigio a las que acceden.

En el sector público, en general, se aplica una valoración social particular a las conductas de hombres y mujeres respectivamente. Esto, genera al interior de las organizaciones la ubicación de las personas en distintos niveles y posiciones, de acuerdo a su sexo. Sin embargo, en el nivel directivo, el estudio revela el acceso a los cargos de poder está mucho más determinado por los grados de participación política de las personas, que por sus condiciones de género. Y eso, no deja de ser interesante. En otras palabras, si se compara el sistema de representaciones de género presente en los sujetos del estudio, con el sistema de representaciones de poder, es precisamente este último el que posee un mayor grado de legitimación al interior del sector público a la hora de definir quién ocupa un cargo directivo. Y quienes están inmersos en ese espacio, hombres y mujeres, perciben la estructura social que se desprende de la participación política como "la única manera" posible de hacer las cosas.

Esta conclusión, de cierta manera ms distancia del tema del poder y nos vuelve a centrar en las representaciones de género, para desde ahí, analizar las vinculaciones que las entrevistadas 
establecieron con los modelos de gestión que ellas desarrollan, comparándolos con aquellos desarrollados por los hombres.

Pero antes de entrar a las vinculaciones propiamente tal, conviene recalcar que de las ideas expresadas en este apartado, esto es, que las mujeres directivas no vinculan la concepción de género a un proceso relacional entre hombres y mujeres, sino más bien es entendido como compartimentos estancos, impenetrables, inabordables para uno $u$ otro. $Y$, por otra parte, que en cuanto a los factores que posibilitan el acceso a cargos de poder, el tema de género deja de ser relevante en comparación con la participación política de las personas que aspiran a dichos cargos. Ese factor es clave en la determinación del acceso, como de la continuidad de una persona en este ámbito.

Estas dos ideas, dan cuenta de una primera respuesta a la hipótesis planteada. Las mujeres con cargos de poder, reproducen la preocupación formal más que la real en relación con tema de género. Su principal atención, al igual que los hombres, está en el tema político, porque de un buen manejo de ese factor dependen, entre otras cosas, su continuidad en dicha posición.

\subsubsection{Vinculaciones entre Género y Modelos de Gestión Pública.}

Género es un proceso de configuración en la práctica social. Se trata de la simbolización cultural en que las diferencias anatómicas y fisiológicas toman forma en prácticas, discursos y representaciones.

Esta mirada conceptual al tema, nos permite introducir las conclusiones referidas a los vínculos establecidos por las entrevistadas con los modelos de gestión que se desarrollan en el Estado, particularmente en el Ministerio de Agricultura.

En las prácticas sociales vinculadas a la gestión, esto es, las tareas de administración y proyección de una organización, se requiere fundamentalmente de legitimidad, entendida ésta última como importantes niveles de capital simbólico surgido a partir del reconocimiento social y del prestigio de las prácticas realizadas.

Pues bien, en el espacio social estudiado, las prácticas de gestión desarrolladas por hombres tienen -en las entrevistadas - una valoración negativa, porque están definidas a partir de los estereotipos de género tradicionales, ya descritos. Sin embargo, los hombres son quienes ocupan un $95 \%$ de los cargos directivos políticos y administrativos del Ministerio de Agricultura, mientras que las mujeres alcanzan solo al $5 \%$.

Estos datos y referencias conceptuales, ayudan a explicar el hecho de que sean las propias mujeres en cargos directivos las que señalan que puestos a elegir, la mayoría de los funcionarios prefieren jefes hombres. $Y$ esto, a pesar de que efectivamente sus estilos de gestión alcanzan niveles de autoritarismo y verticalidad muy altos.

Las preocupaciones (repertorios discursivos) de las mujeres con cargos directivos, sobre el tema de los modelos de gestión, reconoce la primacía del modelo masculino como estructura determinante de las acciones a desarrollar en el sector público. Y en esto, si se concibe la posibilidad de intercambiar roles, es decir, se acepta el hecho de que las definiciones masculinas para una gestión, pueden afectar de igual forma a hombres y mujeres.

Es interesante el hecho de que le otorguen al hombre, en este tema, la posibilidad de aprender a ser femenino en su gestión, pero ven poco probable que un experimento de este tipo llegue a buen puerto en un contexto que califican de patriarcal y machista.

\footnotetext{
${ }^{11}$ Fuente: ODEPA, Oficina de Estudios y Políticas Agrarias del Ministerio de Agricultura.
} 
Si se logra entender que la temática de género centra su potencialidad y dinámica conceptual, a partir de comprender el tema como relacional, complementario, entre hombres y mujeres, se podrá también avanzar en el quiebre de mentalidades o culturas organizacionales que fomentan los liderazgos masculinos (racionales, lógicos, penetrantes, competitivos, autoritarios, verticales) y minimizan la importancia de los aspectos femeninos de las relaciones (manejo emocional, trabajo en equipo, capacidad de delegar, de empatía, etc.).

Se insiste, finalmente, en que las dinámicas de gestión también están cruzadas con el tema del poder, específicamente, al momento de privilegiar cierto tipo de acciones por sobre otras por el hecho de querer resguardar espacios de decisión exclusivos.

Las mujeres directivas actúan, a pesar de sus discursos críticos o de cambio, con parámetros de gestión similares a los hombres. Y en lo que respecta al tema de género, se sigue hablando desde lo "políticamente correcto" y no se salta de la retórica hacia las medidas concretas y específicas.

En estricta justicia, esto trasciende a la voluntad de quienes ejercen cargos políticos y de toma de decisiones, hombres y mujeres, ya que las exigencias y demandas de sus respectivas jefaturas, están ancladas en culturas de trabajo patriarcales, que anulan cualquier intento de apertura hacia espacios más creativos, simbolizados por lo femenino.

En el fondo y de acuerdo a los resultados de este estudio, un primer foco de atención primario respecto de un eventual cambio en la mentalidad de las personas, está en el fomentar el desarrollo de las facetas masculinas y femeninas de cada individuo a través de la educación.

Puestos ya en el lugar de trabajo en el sector público, el tema de género es completamente accesorio y no influye en las tomas de decisiones de las jefaturas, como si lo hacen otros factores enunciados en este trabajo, fundamentalmente, la participación política.

\section{REFERENCIAS BIBLIOGRÁFICAS}

IBAÑEZ, ESÚS. 1997. "Teoría de la Conversación", en: El Regreso del Sujeto. La Investigación Social de Segundo Orden. Editorial Siglo XXI, Madrid.

ALONSO, L. E. "Sujeto y discurso: el lugar de la entrevista abierta en las prácticas de la sociología cualitativa.", en: Métodos y técnicas cualitativas de investigación en Ciencias Sociales. Coordinadores: Delgado, J. M. y Gutiérrez, J. Ed. Síntesis Psicología.España. 1993. Págs. 225-226

PASK, GORDON.1998. "La Teoría de la Conversación", en: Nuevos Avances en Investigación Social y Cibernética. Suplemento de Anthropos. Barcelona.

BOURDIEU, PIERRE. 1999. "La dinámica de los campos", en: La Distinción. Criterios y bases sociales del Gusto. Editorial Taurus, Barcelona.

CEPAL (1999) "Indicadores de Género para el seguimiento y la evaluación del Programa de Acción Regional para las Mujeres de América Latina y el Caribe, 1995 - 2001 y la Plataforma de Acción de Beijing". Santiago de Chile.

CEPAL. 2000. "Las Mujeres Chilenas en los Noventa. Hablan las Cifras".

ERRAZURIZ, M. 1989. "El Gobierno Local como espacio para la acción con Mujeres: promesa que requiere reflexión", en: D. Raczynski y C. Serrano, Políticas Sociales, Mujeres y Gobierno Local, CIEPLAN.

GUZMÁN, V; SALAZAR, R. 1992 "El Género en el Debate de las Políticas Públicas". Centro de Estudios de la Mujer. Proposiciones 21. SUR. Santiago de Chile. 
LAMAS, Marta. 1999. "Género: Los Conflíctos y Desafíos del Nuevo Paradigma". en: Portugal, A. y Torres, C. (edit.): El Siglo de las Mujeres. ISIS Internacional. Santiago de Chile.

MIDEPLAN. 1998. "Situación de la Mujer en Chile", Documento №11 Resultados de Encuesta CASEN 1998.

Ministerio de Bienes Nacionales.1998. "Plan de Igualdad de Oportunidades entre Hombres y Mujeres en el Ministerio de Bienes Nacionales".

Ministerio de Vivienda y Urbanismo. 1999. "Plan de Igualdad de Oportunidades para los funcionarios del Ministerio de Vivienda".

Ministerio de Agricultura. 2000. "Plan de Igualdad de Oportunidades para los funcionarios del Ministerio de Agricultura".

SERNAM - Condición de la Mujer, Canadá. 1998. "Análisis de Género. Guía para la elaboración de Políticas Públicas", en: Perspectiva de género en la función y políticas públicas en Chile. Documento de Trabajo. Santiago de Chile.

SERNAM. 1999. "Cuarto Informe de Avance del Plan de igualdad de Oportunidades para las Mujeres 1994 - 1999". Informe Final (Versión Resumida). Elaborado por Centro de Estudios de la Mujer por encargo del Departamento de Planificación y Estudios del SERNAM.

SERNAM. 2000. "Plan de Igualdad de Oportunidades entre Mujeres y Hombres 2000 - 2010". Lineamientos Generales.

SERNAM.1999. "Los números de la diferencia". Estadísticas de Género

SERNAM .1999. Memoria SERNAM $1994-1999$

SERNAM .1996. "Políticas Públicas para las Mujeres".

SERNAM .1994. "Plan de Igualdad de Oportunidades para las Mujeres 1994 - 1999".

SERNAM. 1992. La relación Mujer-Trabajo en: Las funcionarias de la Administración Pública.

SERRANO, C. 1993. "El trabajo de las mujeres en el sector público". Evaluación y Proposiciones

PARADA, S. 1999 "Empleo Femenino en Chile: El contexto de la precarización del empleo", en: Políticas de lgualdad de Oportunidades entre Hombres y Mujeres en el Trabajo, 1994-1999, SERNAM 